\title{
Game Edukasi Hafalan Surat Pendek Al-Qur'an The Adventure Of Ali
}

\author{
Vadlya Maarif ${ }^{1}$, Hidayat M. Nur ${ }^{2}$, Fitrian Chandrayoga ${ }^{3}$ \\ ${ }^{1}$ Prodi Sistem Informasi, STMIK Nusa Mandiri \\ ${ }^{2}$ Prodi Sistem Informasi, Universitas Bina Sarana Informatika \\ ${ }^{3}$ Prodi Teknologi Komputer, Universitas Bina Sarana Informatika \\ 1vadlya.vlr@nusamandiri.ac.id, ${ }^{2}$ hidayat.hmm@bsi.ac.id, 3fchyoga@gmail.com
}

\begin{abstract}
Games at this time become a very popular thing, even early childhood have played games using an Android smartphone. But children tend to play games excessively, that causing concerns for parent about the negative effects of games that affect their children. Therefore the game "The Adventure of Ali" was created which is a game with an educative concept and is a game as a learning media or educational game. Education itself is very broad in scope, ranging from formal and non-formal education. Memorizing short Al-Qur'an surah is an education that is classified as non-formal, which is non-formal education sometimes tends to be excluded from formal education. So from that the game is made for memorizing short Al-Qur'an surah media, in the form of puzzles in the game. "The Adventure of Ali" is an educational game for memorizing short Al-Qur'an surah that is packaged in adventure and puzzle games that will make children learn without realizing he is learning.
\end{abstract}

Keywords: Games Education, Adventure, Puzzles, Memorizing Short Al-Qur'an Surah, Children, Parents

Abstrak: Game pada saat ini menjadi hal yang sangat popular, bahkan anak-anak usia dini-pun sudah bermain game menggunakan telepon pintar Android. Tapi anak-anak cenderung bermain game dengan berlebihan sehingga menimbulkan kekhawatiran bagi orang tua terhadap efek negatif dari game yang berdampak pada anaknya. Oleh sebab itu dibuatlah game "The Adventure of Ali" yang merupakan game dengan konsep edukatif dan merupakan game sebagai media pembelajaran atau game edukasi. Edukasi sendiri sangatlah luas cakupannya, mulai dari edukasi formal dan non-formal. Menghafal surat pendek Al-Qur'an merupakan suatu edukasi yang tergolong non-formal, yang dimana edukasi non-formal terkadang cenderung tersisih dibandung edukasi formal. Maka dari itu game dibuat untuk media hafalan surat pendek Al-Qur'an berupa puzzle yang ada dalam game. "The Adventure of Ali" merupakan game edukasi hafalan surat pendek Al-Qur'an yang dikemas dalam game petualangan dan puzzle yang akan membuat anak belajar tanpa menyadari dirinya sedang belajar.

Kata kunci: Game Edukasi, Petualangan, Puzzle, Hafalan Surat Pendek Al-Qur'an, Anak-Anak, Orang Tua

\section{A. PENDAHULUAN}

Game pada sekarang ini sudah seperti makanan sehari hari bagi semua orang dan anakanak pada khususnya. Tapi, anak-anak akan cenderung bermain game terlalu berlebihan sehingga melupakan waktu belajar mereka. Apalagi game atau permainan ini adalah suatu bagian tak terpisahkan dari keseharian anak, sedangkan sebagian orang tua mengkhawatrirkan game akan membawa dampak buruk bagi anak seperti nilai yang turun atau bahkan tindak kekerasan akibat meniru perilaku tokoh dalam game. Akan tetapi bukan berarti para orang tua harus langsung melarang anaknya untuk bermain game, akan lebih baik jika menjadikan Game sebagai media belajar. 
Game sebagai media belajar sudah banyak dikembangkan pada saat ini, akan tetapi game yang mengandung kekerasan juga jauh lebih banyak, dan ada potensi anak untuk meniru perilaku tokoh dalam game tersebut, Tetapi sebenarnya, tak ada yang salah dengan perilaku meniru, karena pada dasarnya meniru adalah suatu proses pembelajaran bagi anak-anak bahkan orang dewasa sekalipun. Maka sebenarnya game akan jadi media belajar yang sangat bagus jika dikebangkan dengan konsep edukatif dan dengan penokohan yang baik. Tidak cukup hanya disitu, unsur edukatif itu sendiri sangatlah luas. Edukasi secara umum terbagi menjadi edukasi formal dan non-formal.

Edukasi Formal adalah proses pembelajaran yang sangat umum diselenggarakan yaitu pada sekolah tepatnya dan terdapat peraturan yang berlaku dan wajib untuk di ikuti apabila berada dalam lingkungan sekolah atau saat kegiatan belajar mengajar, kemudian

terdapat pihak terkait dalam pengawasan proses pembelajaran di sekolah. Dalam proses pembelajarannya yang di selenggarakan disekolah terdapat jejang pendidikan yang jelas mulai dari taman kanak-kanak (TK), sekolah dasar (SD), sekolah menengah pertama (SMP), sekolah menengah atas (SMA) sampai pada pendidikan tinggi (Mahasiswa).

Lalu, Edukasi Non-Formal yang berbeda dengan Edukasi Formal, Edukasi Non-Formal biasanya ditemukan di lingkungan tempat kita sendiri, kegiatan / aktivitas edukasi non-formal ini contohnya Taman Pendidikan Al-Quran (TPQ), yang banyak terdapat di Masjid dan Sekolah Minggu, yang terdapat di semua Gereja, Selain itu ada juga tempat kursus musik dan semacamnya.

Mengaji dan Hafalan surat pendek Al-Qur'an yang termasuk kedalam pendidikan Non-Formal terkadang malah tersisihkan oleh Edukasi Formal seperti sekolah formal, padahal keduanya sama pentingnya. Hal ini menjadikan banyak anak yang malas untuk mengaji atau menghafal surat pendek. Maka dari itu membuat suatu media hafalan AI-Qur'an yang menarik bagi anak akan sangat penting.

\section{B. TINJAUAN PUSTAKA}

\section{Game}

Game berasal dari kata bahasa Inggris yang memiliki arti dasar permainan. Permainan dalam hal ini merujuk pada pengertian "kelincahan intelektual" (intellectual playability). Kelincahan intelektual, pada tingkat tertentu, merupakan ukuran sejauh mana game itu menarik untuk dimainkan secara maksimal. Dengan kata lain, segala bentuk kegiatan yang memerlukan pemikiran, kelincahan intelektual dan pencapaian terhadap target tertentu dapat dikatakan sebagai game. Menurut Jasson dalam [Saputra and Rafiqin, 2017] "Game adalah suatu system atau program dimana satu atau lebih pemain mengambil keputusan melalui kendali pada obyek di dalam game untuk suatu tujuan tertentu".

Adapun pengertian game menurut Wardhani, dkk dalam [Saputra and Rafiqin, 2017] "Game (permainan) secara umum adalah sebuah aktivitas rekreasi dengan tujuan bersenang-senang, mengisi waktu luang, atau berolahraga ringan. Permainan biasanya dilakukan sendiri atau bersama-sama". Sedangkan menurut Leyton-Brown dan Shoham dalam (Agustina dan Wahyudi, 2015) "Game atau permainan adalah suatu cara belajar dengan menganalisa dengan sekelompok pemain maupun indvidual dengan menggunakan stragtegi-strategi yang rasional".

Berdasarkan beberapa penjelasan diatas dapat disimpulkan bahwa game adalah suatu system atau program dimana satu atau lebih pemain mengambil keputusan melalui

kendali pada obyek di dalam game dengan tujuan bersenang-senang, mengisi waktu luang, atau berolahraga ringan dimana pemain belajar menganalisa menggunakan strategi-strategi rasional yang memerlukan pemikiran, kelincahan intelektual dan pencapaian terhadap target tertentu.

\section{Android}

Menurut Dodit Suprianto dan Rini dalam [Lengkong et al., 2015] "Android merupakan subset perangkat lunak untuk perangkat mobile yang meliputi sistem operasi, middleware, dan aplikasi inti yang dirilis oleh Google".

Android adalah sistem operasi bergerak (mobile operating system) yang mengadopsi sistem operasi linux, namun telah dimodifikasi. Android diambil alih oleh Google pada tahun 2005 dari Android,Inc sebagai bagian strategi untuk mengisi pasar sistem operasi bergerak. Google mengambil alih seluruh hasil kerja Android termasuk tim yang mengembangkan Android. 


\section{Metode Hafalan Surat Pendek Al-Qur'an}

Menurut [Hidayah and Ulva, 2017] beberapa metode yang diterapkan dalam mengajari anak usia dini menghafal al-Qur'an adalah sebagai berikut.

a) Metode talqin

Mengajarkan anak menghafal al-Qur'an dengan metode ini adalah dengan cara membacakan terlebih dahulu ayat yang dihafal secara berulang-ulang hingga anak menguasainya. Setelah anak menguasai, maka berpindah ke ayat selanjutnya.

b) Metode talqin dan mendengarkan rekaman

Metode ini hampir sama dengan metode pertama. Perbedaannya adalah talqin dalam metode ini hanya dilakukan sekali. Langkah selanjutnya adalah memperdengarkan ayat-ayat yang dihafal melalui rekaman bacaan ayat tersebut dari qari' ternama di dunia, seperti Muhammad Ayub, al-Hushari, al-Ghamidy, dan sebagainya. Rekaman ini diputar berulang kali sehingga anak hafal di luar kepala.

c) Metode gerakan dan isyarat

Cara menghafal al-Qur'an dengan metode ini dipelopori oleh ayah Husein athThaba'thaba'i yang berhasil menjadikan anaknya ahlul qur'an sejak usia 6 tahun. Metode ini cocok untuk anak yang mempunyai daya konsentrasi pendek dan tidak bisa diam. Metode ini menarik bagi anak yang kurang tertarik dengan lafadz-lafadz ayat yang sedang dihafal.

Sebagai contoh penggunaan metode ini adalah ketika menghafal ayat"wa aqiimush shalata, guru melakukan takbir sebagai isyarat shalat, lalu pada lafadz "wa atuz zakata, mereka menghentakkan tangan kanan seakan mengeluarkan zakat, dan warka'u ma'ar raki'in, mereka melakukan ruku'.

Ketika menggunakan metode ini, guru harus benar-benar bisa memahami benar makna dari ayat yang dihafalkan. Di samping itu, guru juga harus kreatif dalam melakukan gerakan. Kelebihan metode ini adalah, anak tidak hanya menghafalkan ayat al-Qur'an saja, tetapi juga maknanya. Adapun kekurangan metode ini, bagi penulis adalah bahwa gerakan dan isyarat tubuh terlalu sempit untuk menggambarkan makna ayat al-Qur'an, apalagi jika berhadapan dengan ayat yang bersifat abstrak dan cakupannya luas.

d) Metode membaca ayat yang akan dihafal

Metode ini mensyaratkan bahwa anak sudah bisa baca al-Qur'an dengan baik. Dengan kata lain, anak menghafal sendiri dengan membaca ayat al-Qur'an yang dihafal secara berulang-ulang, kemudian baru menghafalkannya. Metode ini diterapkan oleh santrisantri al-Utrujah Jakarta yang bisa menyelesaikan hafalan 10 juz dalam waktu 10 bulan. Dengan demikian, satu bulan mereka berhasil menghafal 1 juz.

e) Metode menghafal dengan merekam suara guru dan anak

Metode ini menggunakan media alat perekam dan membutuhkan partisipasi orang tua atau guru. Jika orang tua telah fasih dalam membaca al-Qur'an dan sudah menghafalkannya secara sempurna, maka sangat dianjurkan orang tua yang bertindak sebagai guru di sini. Akan tetapi, jika tidak, maka orang lain pun bisa jika memenuhi kriteria di atas.

Langkah pertama adalah persiapkan alat perekam. Sementara alat perekam tersebut sudah diaktifkan, orang tua membaca ayat-ayat yang akan dihafal. Selanjutnya orang tua memerintahkan anak membacanya. Pastikan bahwa alat perekam telah merekam dengan baik suara bacaan orang tua dan anak. Minta lah anak mendengarkan secara berulang-ulang hingga dia menghafalnya dengan sempurna. Tentukan waktu kapan setiap hari orang tua akan menguji hafalannya tersebut.

Metode ini sangat bagus, mengingat anak kecil suka mendengarkan suaranya sendiri. Di samping itu, dengan adanya dua macam bacaan ayat al-Quran tersebut, yakni suara orang tua dan suara anak, maka si anak pun dapat mengetahui kesalahankesalahannya dengan membandingkan dengan bacaan orang tuanya.

Kelebihan lainnya, adalah metode ini mengajarkan anak menghafal secara mandiri dan orang tua pun bisa lebih fleksibel mengerjakan pekerjaan lainnya. Metode ini pun cocok diterapkan untuk keluarga modern yang para orang tua sibuk bekerja atau beraktifitas di luar rumah, tapi mendambakan anak-anak yang hafal al-Qur'an.

f) Metode memperdengarkan rekaman bacaan ayat al-Qur'an dari guru dan anak sebayanya 
Metode ini hampir sama dengan metode sebelumnya. Perbedaannya hanyalah si anak tidak mendengarkan suaranya sendiri, tetapi suara anak sebayanya. Langkahlangkahnya adalah sebagai berikut.

1) Seorang guru merekam bacaan ayat yang akan dihafal, kemudian diikuti oleh empat anak yang memiliki suara bagus, baik dari makhraj maupun kejernihan suaranya. Mereka membaca hingga berulang-ulang kali dengan cara yang sama.

2) Rekaman tersebut diperdengarkan kepada anak-anak di rumah, dengan pertimbangan tempat yang tidak bisa dijangkau anak-anak. Anak-anak dibiarkan bermain-main atau pun melakukan hal menyenangkan lainnya. Dengan demikiann, anak-anak dengan sendirinya akan menghafalkan bacaan tersebut, bahkan mereka akan mengulang-ulangi ketika mereka bertemu teman-temannya. Metode ini diterapkan berdasarkan asumsi bahwa anak suka meniru anak sebayanya, sehingga ketika mereka mendengar suara anak sebayanya, mereka cenderung ingin menirunya. Metode ini cocok untuk ibu-ibu rumah tangga yang sering melakukan banyak pekerjaan rumah..

\section{Flowchart}

Menurut [Widayanto et al., 2017] "Flowchart adalah suatu diagram yang menggambarkan susunan logika suatu program dan industri manufacturing".

Pada dasarnya, Diagram Alir (Flowchart) adalah alat yang digunakan untuk melakukan perencanaan proses, analisis proses, dan mendokumentasikan proses sebagai standar pedoman program. Selain itu, flowchart juga digunakan untuk mendokumentasikan standar proses yang telah ada dan melakukan analisis terhadap proses sehingga dapat menjadi pedoman dan dapat melakukan peningkatan atau perbaikan proses yang berkesinambungan.

Flowchart ini berbentuk sebuah diagram yang mewakili algoritma atau proses dengan berbagai jenis kotak-kotak dan dihubungkan oleh garis-garis panah sebagai arah alurnya.

\section{HIPO (Hierarchy Input Proses Output)}

HIPO (Hierarchy Input Proses Output) merupakan metodologi yang dikembangkan dan didukung oleh IBM. HIPO sebenarnya adalah alat dokumentasi program. Akan tetapi sekarang, HIPO juga banyak digunakan sebagai alat disain dan teknik dokumentasi dalam siklus pengembangan sistem. HIPO berbasis pada fungsi, yaitu tiap-tiap modul di dalam sistem digambarkan oleh fungsi utamanya.

\section{METODE PENELITIAN}

Metode penelitian yang digunakan dalam akhir pembuatan game "The Aventure of Ali: Perjalanan Pulang" ini adalah Metode Pengumpulan Data. Pengumpulan data dilakukan untuk mendapatkan suatu informasi yang dibutuhkan dalam mencapai tujuan penelitian. Dan metodenya adalah sebagai berikut:

\section{Observasi}

Metode pengumpulan data pertama yang dilakukan yaitu Observasi atau Pengamatan. Pengamatan dilakukan terhadap anak-anak dibawah usia dini yang sudah bermain game, mengamati minat anak-anak terhadap game dan minat anak terhadap hafalan Al-Qur'an.

\section{Wawancara}

Metode pengumpulan data berikutnya yaitu wawancara. Wawancara dilakukan terhadap orang tua yang mempunyai anak yang suka bermain game, untuk mengetahui hal apa saja yang menjadi hal positif dan negatif dari anak yang bermain game, dan kekhawatiran apa saja jika anak bermain game.

\section{Studi Pustaka}

Metode pengumpulan data yang terakhir yaitu studi pustaka. Studi pustaka pada buku, jurnal, e-book, dan website serta ensiklopedia sebagai media pencarian dengan pengumpulan data serta informasi untuk menambah referensi dalam pembuatan game "The Adventure of Ali: Perjalanan Pulang". 


\section{HASIL DAN PEMBAHASAN}

\section{Perumusan Ide}

Perumusan ide adalah salah satu proses awal pembuatan game dimana keseluruhan ide yang meliputi elemen cerita, elemen teknologi, gameplay, dan target serta tujuan game bersama-sama dirumuskan dan dikembangkan.

Ide-ide dalam pembuatan game "The Adventure of Ali: Perjalanan Pulang" ini yaitu sebagai berikut.

a. Elemen Cerita

Elemen Cerita dalam perumusan ide disini meliputi jalan cerita dan nilai-nilai edukatif yang akan dimasukan ke dalam game ini. Jalan cerita game ini yaitu tentang petualangan seorang anak bernama Ali dalam perjalanan pulang setelah berkunjung ke rumah saudaranya, yang dimana perjalanan tersebut menjadi sebuah petualangan yang mengharuskan Ali untuk melawan Setan jahat dengan cara mengaji dan sholat.

Nilai-nilai edukatif dalam game ini meliputi watak tokoh utama, perilaku tokoh utama, serta alur cerita pada game. Terutama pada perilaku tokoh utama yang melawan Setan dengan cara mengaji akan mengharuskan pemain game untuk menghafalkan suratsurat pendek yang akan menjadi misi dalam game.

Dengan elemen cerita di atas dapat ditentukan gameplay dan elemen keindahan pada game ini.

b. Elemen Teknologi

Elemen teknologi meliputi perangkat yang dapat memainkan game ini. Game "The Adventure of Ali: Perjalanan Pulang" dibuat untuk perangkat mobile berbasis Android.

c. Gameplay

Gameplay berarti memainkan permainan tetapi biasa didefinisikan sebagai interaksi antara user dengan sebuah game yang dimainkan yang berkenaan dengan aturan bermain serta hal apa saja yang harus dipenuhi dalam permainan.

Gameplay pada game "The Adventure of Ali: Perjalanan Pulang" yaitu pemain harus mengikuti alur cerita dimana Ali harus mencari jalan untuk pulang ke rumah dalam genre 2D Platformer, selain itu pemain harus mencari Pak Ustadz sebagai guru mengaji Ali, disini pemain harus menyelesaikan Puzzle surat pendek Al-Qur'an dan sebelum menyelesaikan Puzzle pemain menghafal terlebih dahulu surat pendek yang akan di bacakan oleh Pak Ustadz. Setelah mengaji Ali akan mendapatkan skill untuk melawan Setan, pemain dapat menekan tombol agar Ali dapat mebacakan doa kepada Setan yang dilawan.

Ali juga memiliki HP (Health Point) dan juga EP (Energy Point). EP dapat dikumpulkan pemain dengan cara Ali Sholat di Masjid yang akan terdapat acak pada masing-masing level, dan EP akan berkurang setelah Ali menggunakan skillnya untuk berdoa melawan Setan, yang mengharuskan Ali Sholat kembali untuk membuat EP Ali penuh kembali. Sedangkan HP Ali juga berkurang jika menyentuh atau diserang oleh Setan, maka pemain harus membuat Ali menghindar dan dengan cepat untuk menggunakan skill untuk berdoa melawan Setan. HP dapat dipulihkan dengan cara Ali memakan buahbuahan yang ada di hutan atau tidur untuk memulihkan HP sampai $100 \%$.

d. Target dan Tujuan Game

Target game "The Adventure of Ali: Perjalanan Pulang" adalah untuk anak-anak usia dini, dengan tujuan agar anak-anak dapat belajar tanpa menyadari dirinya sedang belajar, dan mempermudah anak-anak menghafal surat pendek Al-Qur'an

\section{Perumusan Mekanik}

Perumusan mekanik merupakan proses pembuatan game dimana keseluruhan elemen mekanik yang meliputi ruang, objek, dan aturan yang ada dalam game bersama-sama dirumuskan berdasarkan hasil perumusan ide.

Elemen mekanik dalam pembuatan game "The Adventure of Ali: Perjalanan Pulang" ini yaitu sebagai berikut.

a. Ruang

Ruang dalam perumusan mekanik disini adalah sebagai tempat dimana semua objek didalam game saling berinteraksi. Pada aplikasi Contruct 2, ruang di representasikan sebagai layout yang merupakan tempat dimana semua objek yang akan ditampilkan 
pada user interface game diletakan dan ditata dengan sedemikian rupa sesuai dengan hasil perumusan ide.

b. Objek

Objek pada Construct 2 merupakan keseluruhan hal yang ada didalam game, khususnya pada game "The Adventure of Ali: Perjalanan Pulang" objeknya meliputi sprite, tiled background, input touch, local storage, dan audio.

c. Aturan

Aturan pada Contruct 2 yaitu berupa event sheet yang merupakan halaman untuk menambah aturan dan fungsi serta logika dalam game. event sheet berfungsi untuk mengatur keseluruhan objek yang ada dalam game agar dapat berjalan sesuai dengan hasil perumusan ide.

\section{Penambahan Unsur Keindahan}

Penambahan unsur keindahan merupakan proses pembuatan game dimana keseluruhan elemen keindahan yang meliputi keindahan visual dan keindahan suara bersama sama ditambahkan kedalam game.

Elemen keindahan dalam pembuatan game "The Adventure of Ali: Perjalanan Pulang" ini yaitu sebagai berikut.

a. Keindahan Visual

Elemen keindahan visual yaitu keseluruhan desain objek pada game yang meliputi desain karakter, desain background, dan desain objek penyusun game lainnya.

b. Keindahan Suara

Elemen keindahan suara yaitu keseluruhan audio yang akan diputar dalam game yang meliputi audio efek game, dan audio surat pendek Al-Qur,an yang akan menjadi audio pendukung pada puzzle hafalan dan mejadi audio efek Skill dalam game.

\section{HIPO}

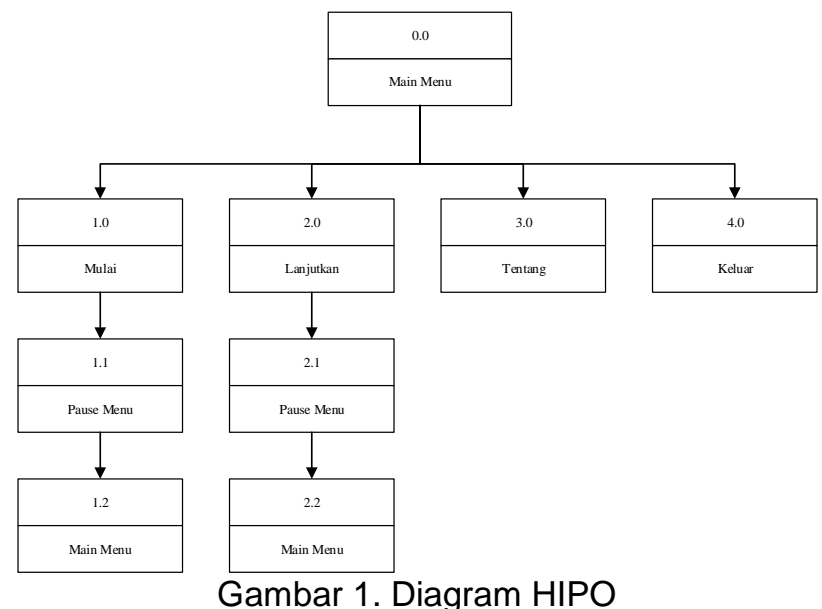




\section{Flowchart}

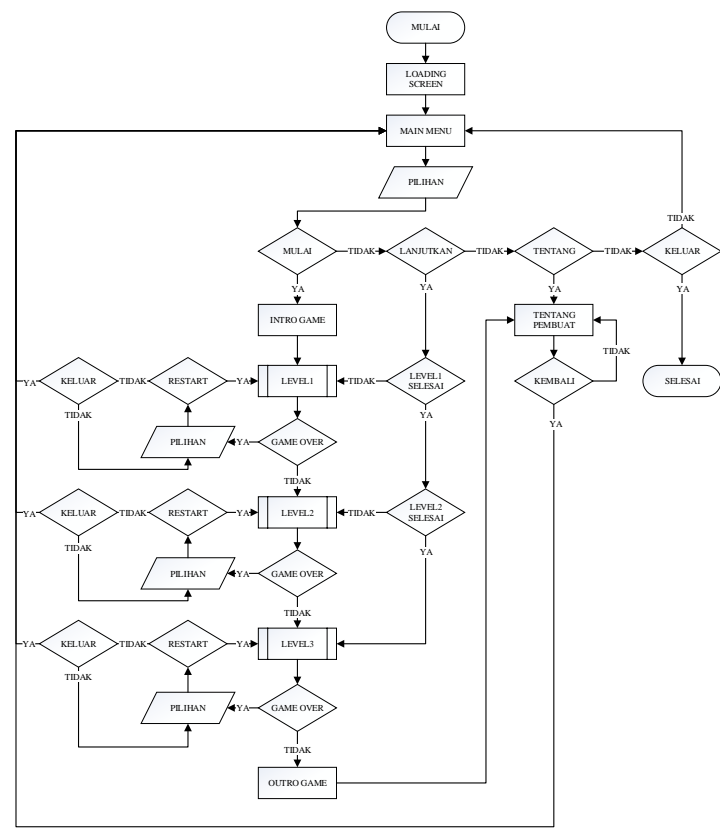

Gambar 2. Flowchart Game

\section{Implementasi}

a) Main Menu

b) Intro Game

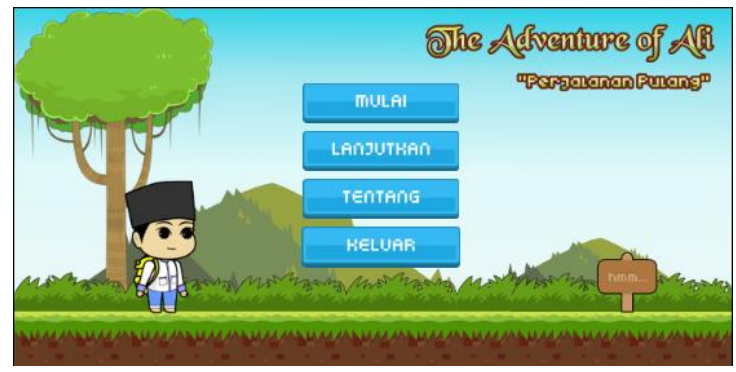

Gambar 3. Main Menu

\section{STOR'Y}

Hari ini seharusnya Ali pulang dari rumah seaudara setelah berkunjung, tapi saudara Ali tidak bisa mengantar karena motornya rusak.

Karena Ali tidak mau membuat repot saudaranya sehingga dia memutuskan pulang sendiri dengan jalan kaki.

Tapi, perjalanan pulang Ali tidak selancar yang di bayangkan karena harus melewati hutan. dan Petualangan pun di mulai..

$$
\text { mULFII }
$$

Gambar 4. Intro Game 
c) Platformer Level

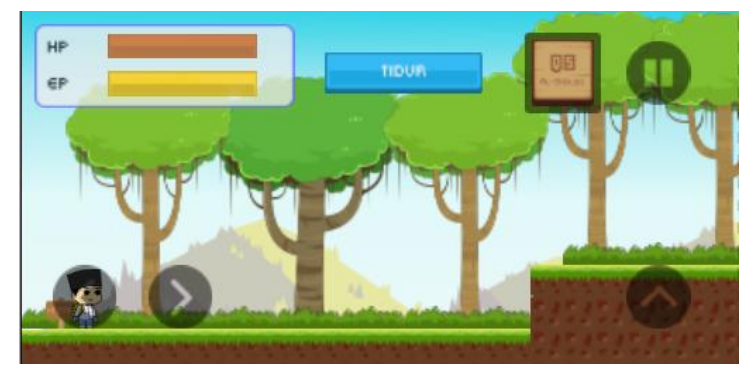

Gambar 5. Platformer Level

d) Puzzle Level

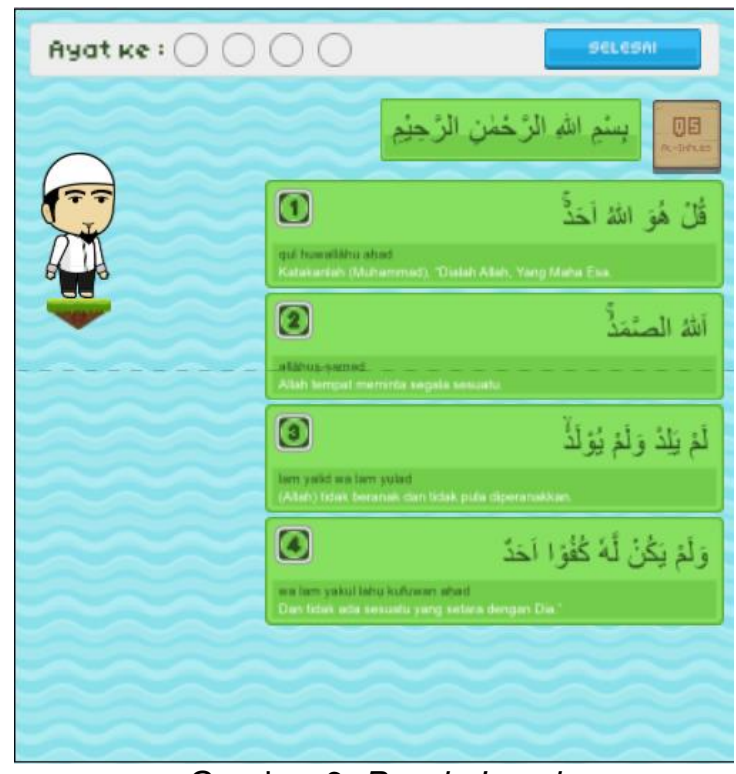

Gambar 6. Puzzle Level

e) Cutscene Game

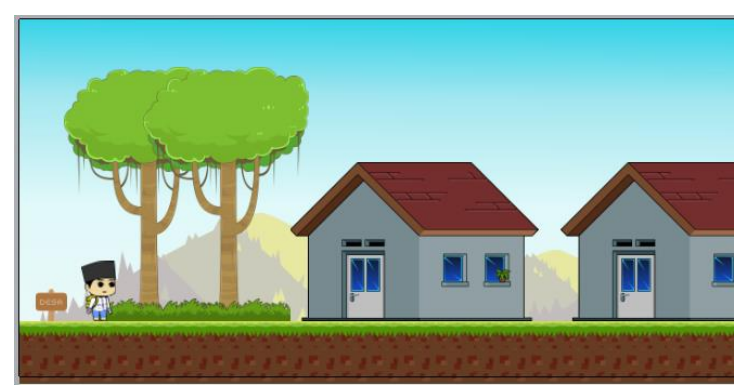

Gambar 7. Cutscene Game

f) Outro Game

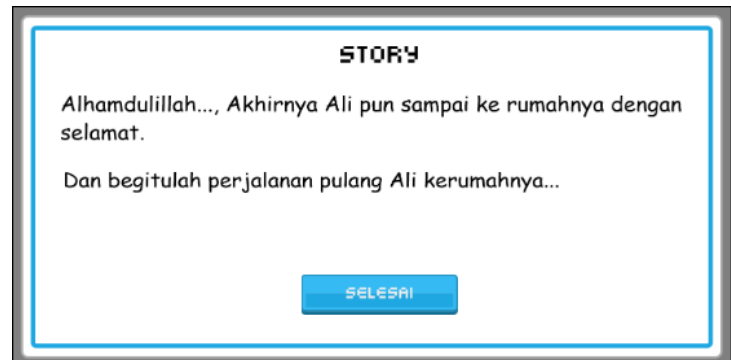

Gambar 8. Outro Game 


\section{E. KESIMPULAN}

Dibuatnya game "The Adventure of Ali: Perjalanan Pulang" diharapkan dapat membuat anak-anak dapat belajar tanpa menyadari dirinya sedang belajar, dan dapat menambah minat anak-anak dalam menghafal surat pendek Al-Qur'an, serta mengurangi kekhawatiran orang tua terhadap anak yang bermain game. Adapun kesimpulan sebagai berikut.

1. Game "The Adventure of Ali: Perjalanan Pulang" dapat menjadi pilihan game untuk anakanak usia dini.

2. Game "The Adventure of Ali: Perjalanan Pulang" dapat menjadi game pilihan orang tua yang mengkhawatirkan dampak negatif dari game bagi anaknya, karena game ini memiliki nilai-nilai edukatif yang baik unutk anak-anak.

3. Game "The Adventure of Ali: Perjalanan Pulang" adalah game sebagai media pembelajaran atau game edukasi untuk media hafalan surat pendek Al-Qur'an

4. Surat pendek Al-Qur'an yang menjadi materi hafalan yaitu surat An-Nas, surat Al-Falaq, dan surat Al-Ikhlas..

\section{REFERENSI}

Hidayah N, Ulva RK. 2017. Pengembangan Media Pembelajaran Berbasis Komik Pada Mata Pelajaran IImu Pengetahuan Sosial Kelas IV MI Nurul Hidayah Roworejo Negerikaton Pesawaran. Terampil J. Pendidik. dan Pembelajaran Dasar 4: 34-46.

Lengkong HN, Sinsuw AAE, Lumenta ASM. 2015. Perancangan Penunjuk Rute Pada Kendaraan Pribadi Menggunakan Aplikasi Mobile Gis Berbasis Android Yang Terintegrasi Pada Google Maps. E-Journal Tek. Elektro Dan Komput. 4: 18-25.

Saputra D, Rafiqin A. 2017. Pembuatan Aplikasi Game Kuis "Pontianak Punye" Berbasis Android. J. Khatulistiwa Inform. V: 71-85.

Widayanto A, Suleman, S IA. 2017. Rancang Bangun Aplikasi Kategori Bahasa Untuk Tuna Wicara Berbasis Android. Evolusi J. Sains dan Manaj. 5. 